\title{
THE ILLUSION OF INDEPENDENT AGENCY: DO ADULT FICTION WRITERS EXPERIENCE THEIR CHARACTERS AS HAVING MINDS OF THEIR OWN?
}

MARJORIE TAYLOR

SARA D. HODGES

ADĖLE KOHÁNYI

University of Oregon, Eugene

\author{
NOTICE \\ This materint may be \\ protected by copyriopt \\ law (iitie 17, U.S. Corda)
}

\begin{abstract}
The illusion of independent agency (IIA) occurs when a fictional character is experienced by the person who created it as having independent thoughts, words, and/or actions. Children often report this sort of independence in their descriptions of imaginary companions. This study investigated the extent that adult writers experience IIA with the characters they create for their works of fiction. Fifty fiction writers were interviewed about the development of their characters and their memories for childhood imaginary companions. Ninety-two percent of the writers reported at least some experience of IIA. The writers who had published their work had more frequent and detailed reports of IIA, suggesting that the illusion could be related to expertise. As a group, the writers scored higher than population norms in empathy, dissociation, and memories for childhood imaginary companions.
\end{abstract}

Children begin to pretend in the second year of life with simple acts such as sipping imaginary milk from an empty cup. Over the preschool years, they quickly become capable of complex and often highly imaginative pretense [1-3]. However, pretend play has often been described as declining as children enter middle childhood and turn to other activities such as games with rules [4]. Recently, researchers have 
argued that this developmental story seriously underestimates pretending in older children and the extent to which individual differences in childhood pretending relate to later types of imaginative activities $[5,6]$. Our view is that children's early developing capacity and strong inclination to engage in pretend play is fundamental to human cognition and that pretend play, in some form, continues to have an important role, even in the lives of adults. In this research we investigated the possibility that the creation of an imaginary companion, a type of pretend play that is strongly associated with early childhood, has analogues in the activities of adult fiction writers.

An imaginary companion is a character invented by a child who plays or interacts with it on a regular basis. According to the most recent accounts, about $65 \%$ of children under seven years of age have a history of play with imaginary companions [5, 7]. Little is known about the fate of childhood imaginary companions, but published diaries and biographies provide evidence that at least a few of them continue into adulthood in a diminished role or as a cherished memory. For example, in her painting "The Two Fridas," Frida Kahlo, the famous Mexican artist, portrayed herself holding hands with an imaginary friend who was like an identical twin. As an adult, Kahlo also wrote in her diary about her attachment to her childhood imaginary friend [8]. Kurt Cobain, the lead singer of the rock band Niryana, had an imaginary friend named Boddha when he was a little boy. His imaginary friend must have still been important to him as an adult because when Cobain committed suicide in 1994, he addressed his suicide note to Boddha [9].

Apart from such isolated reports, not much is known about the traces of childhood imaginary friends in the lives of adults. However, perhaps a more productive line of inquiry would be to consider a wider range of fantasy activities enjoyed by adults, instead of looking for imaginary companions in the exact form that they occur in childhood. Probably most adults enjoy some sort of activity involving fantasy consumption (e.g., films, theater, novels), but the more closely related comparison with childhood imaginary companions involves adult production of fantasy material. Adult fantasy production includes a wide range of activities such as role-playing in games (e.g., "Dungeons and Dragons") or on the Internet, historical re-enactments like those of the "Society for Creative Anachronism," and acting in theatrical or film productions. We think, however, that the adult activity most closely aligned with having imaginary friends is the creation of fictional characters by novelists, playwrights, and screenwriters. Like children who regularly imagine the exploits of pretend friends, writers, on a daily basis, imagine fictional characters and the invented worlds they inhabit. We suspected that taking a closer look at the relationship between writers and their characters might provide insight about the phenomenology of elaborate fantasy for pretenders of all ages. 
- ADULT FICTION WRITERS AND THEIR CHARACTERS

At first glance, the activities of an adult fiction writer might seem far removed from those of a child playing with an imaginary companion. Children have personal interactive relationships with their imaginary friends; they play together, have conversations, and share the events of daily life in the real world. In contrast, the job of writing a story about an imagined character who lives in a fictional world requires less personal involvement. Thus, writers might stay more psychologically removed from their characters. However, when we surveyed accounts of the writing process, we were struck by the number of authors who described having personal relationships with their characters and imagined conversations with them. For example, Francine de Plessis Gray described her characters as sleeping in her bed with her and sometimes waking her up to ask about her plans for their future [10]. Alice Walker reported having lived for a year with her characters Celie and Shug while writing the novel The Color Purple. Walker writes, "Just as summer was ending, one or more of my characters-Celie, Shug, Albert, Sofia, or Harpo-would come for a visit. We would sit wherever I was, and talk. They were very obliging, engaging, and jolly. They were, of course, at the end of their story but were telling it to me from the beginning. Things that made me sad, often made them laugh. Oh, we got through that; don't pull such a long face, they'd say" [11, p. 359].

In these accounts, writers describe their characters as autonomous beings who exist and act outside of their authors' control and have minds of their own. They arrive fully formed in the mind's eye and are resistant to change. For example, when J. K. Rowling, the author of the best-selling Harry Potter books for children, was asked in a National Public Radio interview why she made her main character a boy, she answered that she had tried to make him a girl. "About six months into writing the book, I thought that I am female, and that he is a boy. But it was too late, it was too late to make Hanry Harriet. He was very real to me as a boy, and to put him in a dress would have felt like Harry in drag. . . I never write and say, 'OK, now I need this sort of character.' My characters come to me in this sort of mysterious process that no one really understands, they just pop up" [12].

Sometimes characters are described as having definite opinions about the narrative in which they live. They argue with the author about the direction the novel is taking and their actions in it. In a Canadian Broadcasting Corporation radio interview, Sara Paretsky described making a deal with her recurring character V. 1. Warshawski. The story line in her novel Hard Time required that Warshawski go to prison where she was beaten up, tortured, and almost killed. V. I. "refused" to go along with this until the author promised to give her true love in exchange. Similarly, Philip Pullman, author of "His Dark Materials Triology," described having to negotiate with a particularly proud and high strung 
character, Mrs. Coulter, to make her spend some time in a cave at the beginning of "The Amber Spyglass" [13]. In some accounts, the fictional characters do not limit their opinions to the world of the novel. They also provide unsolicited advice about matters concerning the author's real life [10].

Another component of the description of characters coming to life in this way is that some writers report that their novel seems be dictated to them, or that the characters are the ones who are working out the plot [10]. This sort of description is quite common and can be found in interviews and writings of authors as varied as Henry James, Jean Paul Sartre, Fyodor Dostoevsky, Marcel Proust, Kurt Vonnegut, Sue Grafton, and Quentin Tarantino. For example, Proust is reported to have answered a reader who complained that the character Swann had become ridiculous by replying that Swann reached this state in "spite of Proust's intention as author" $[14$, p. 87]. Similarly, John Fowles includes a description of authors, losing control of their stories as part of his narrative in Chapter 7 of The French Lieutenant's Woman:

You may think novelists always have fixed plans to which they work, so that the future predicted by Chapter One is always inexorably the actuality of Chapter Thirteen. We (novelists) know a world is an organism, not a machine. We also know that a genuinely created world must be independent of its creator; a planned world (a world that fully reveals its planning) is a dead world. It is only when our characters and events begin to disobey us that they begin to live. When Charles left Sarah on her cliff edge, I ordered him to walk straight back to Lyme Regis. But he did not; he gratuitously turned and went down to the Dairy.

Oh, but you say, come on-what I really mean is that the idea crossed my mind as I wrote that it might be more clever to have him stop and drink milk ... and meet Sarah again. That is certainly one explanation of what happened; but I can only report-and I am the most reliable witness-that the idea seemed to me to come clearly from Charles, not myself [15, pp. 96-97].

This experience of characters contributing to or rebelling against the author's vision of a story also appears in E. M. Forster's comments on the process of writing a novel:

The characters arrive when evoked, but full of the spirit of mutiny. For they have these numerous parallels with people like ourselves, they try to live their own lives and are consequently often engaged in treason against the main scheme of the book. They "run away," they "get out of hand": they are creations inside of a creation, and often inharmonious towards it; if they are given complete freedom they kick the book to pieces, and if they are kept too sternly in check, they revenge themselves by dying, and destroy it by intestinal decay [16, pp. 66-67].

In her book Invisible Guests, Mary Watkins presents many more examples taken from the autobiographies and biographies of famous writers which document their impression that it is the characters who narrate the story to them. In 
these descriptions, the events of the story are generated by the characters' actions and the writer's job becomes merely to observe the story as it unfolds, almost as one would experience a dream. Thus, a story narrative can take unexpected turns that surprise the author, although they originated in his or her own head. For example, Enid Blyton writes:

As I look at them, the characters take on movement and life--they talk and laugh (Thear them), ... I don't know what anyone is going to say or do. I don't know what is going to happen. I am in the happy position of being able to write a story and read it for the first time, at one and the same moment. . . . Sometimes a character makes a joke, a really funny one, that makes me laugh as I type it on the paper and I think, "Well, I couldn't have thought of that myself in a hundred years!" And then I think, "Well, who did think of it, then?" [17, pp. 206-207].

\section{PARALLELS WITH DESCRIPTIONS OF CHILDHOOD IMAGINARY COMPANIONS}

The accounts of adult authors describing the writing process have some intriguing parallels with descriptions of childhood imaginary companions, particularly in terms of the characters developing minds of their own. Taylor [7] has collected several accounts of imaginary companions that include references to uncontrollability. One adult reported that between the ages of three and five, he enjoyed the company of two invisible boys: Hood, who functioned as a regular playmate and was similar in most respects to the boy himself, and Bing, who was smarter and generally superior to both Hood and the boy. Bing had a better sense of humor, more impressive things to say, and more interesting things to do. In fact, he was often too busy to play; he was experienced as having a mind and life of his own. A large part of what the adult recalled about having imaginary companions was his conversations with Hood about Bing-wondering what he was doing that day and if he would show up to play-and his feelings of longing for him.

It is not unusual for imaginary companions to have this sort of independence. Sometimes they do not go away when the child wishes they would, but instead follow the child around in a way that is described as annoying. Others, like Bing, do not always show up when they are wanted. Children also express complaints about imaginary companions who talk too loud, do not share, or do not do as they are told. Adults might interpret reports of autonomy in a pretend friend as evidence that the child is confused about the friend's fantasy status or even as suggesting a dissociative disorder. Actually, we might have similar suspicions about an adult who described imagined characters as having minds of their own-until the adult is identified as a novelist. In the positively-regarded context of creative writing, we are willing to accept the possibility of phenomenological peculiarities; we do not question the adult's mental health. Writers certainly become immersed in the fantasy worlds they create and, as they work, may lose track of their real-world 
surroundings, but we doubt that novelists are seriously confused about the fantasy/ reality distinction. In the case of children, it is also possible that their grasp of the fantasy-reality distinction is independent of their perception of imaginary friends as autonomous. Yet, on the occasions that an imagined character is experienced as thinking and acting independently, he or she must seem eerily real.

The similarities in the descriptions collected from adults and children suggest that the experience of imaginary others as autonomous might be part of the phenomenology of sustained fantasy for pretenders of all ages. This possibility raises some interesting questions. First of all, not all children report autonomy in their imaginary comparisons. In fact, for some children it appears that having an imaginary companion under one's thumb is exactly what they like about the fantasy. Under what conditions do imagined characters become autonomous and what does this mean for the understanding or enjoyment of the fantasy experience? One way to develop hypotheses and gain understanding of the phenomenology of childhood fantasy is to look for parallels in the experiences of adults, who are better able to describe their fantasy activities than young children. Thus, in this research, we have moved beyond collecting anecdotes about famous authors to a more systematic investigation of the relationship that develops between adult writers and their fictional characters.

\section{THE ILLUSION OF INDEPENDENT AGENCY}

According to the reports of adult authors described above, fictional characters are often experienced by their creators as having their own thoughts, feelings, and actions. The essence of this conceptual illusion is the sense that the characters are independent agents not directly under the author's control. As a consequence, writing becomes more like passive reporting than active creation. After all, once a writer feels as if the characters are acting independently, it follows that the writer would no longer have the sensation of "composing" fiction. The experience of this sort of autonomy in fictional characters is referred to here as the illusion of independent agency (IIA).

Although the illusion of independent agency is a very specific type of experience that occurs in the context of fantasy production, we see a number of connections to recent investigations of automatic and controlled processes in cognitive and social psychology. First of all, there is growing evidence that people often fail to recognize their own causal role in outcomes in which they do play a part $[18,19]$. This research has focused on perceptions of involuntary behavior in the motor realm (e.g., people are unaware of the small movements they have produced that make a dowsing rod twitch), but opens the door to the possibility that a person could be unaware of the thought processes giving rise to a sense of what a character is saying or doing. Research on reality monitoring also provides evidence of cases in which people sometimes misattribute selfgenerated images to other sources [20]. 
The illusion of independent agency is also related in some respects to the state of "flow," described by Csikszentmihalyi [21]. Flow refers to the pleasurable experience of becoming so totally absorbed in an activity that the sense of the passage of time is suspended, one loses track of the self and immediate surroundings, and the activity becomes effortless and unselfconscious. Authors often report the experience of flow while writing [22], and we suspect that flow might facilitate the development of autonomy in fictional characters. Note, however, that flow differs from the illusion of independent agency in important ways. First of all, authors' accounts of flow do not necessarily include the type of personal interactions with characters that we are investigating. Moreover, the illusion of independent agency is often characterized by conflict between the character and the author, which is in marked contrast to the effortlessness that is the hallmark of flow. Nevertheless, flow and the illusion of independent agency are similar in that both seem to involve the automatization of the creative process and may be associated with the development of expertise.

Research on skill acquisition has shown that many goal-directed processes become increasingly efficient with practice until they operate without conscious guidance [23]. Thus, becoming an expert involves an increasing amount of automatization. When a person first starts to operate within a domain-driving a car, playing chess, or making medical diagnoses--judgments and behavior come slowly with lots of conscious, effortful thinking and reasoning. For example, the demands of operating a car (e.g., shifting gears, attending to traffic lights, changing lanes, etc.) might make it difficult or even dangerous for the novice driver to participate in a conversation with a passenger at rush hour. With increased expertise, however, the process of operating the car becomes automatized, freeing the driver's conscious attentional capacity for other tasks. It becomes possible to listen to music or have a conversation, while continuing to drive safely.

Perhaps someone who pretends a lot-a child who regularly plays with an imaginary companion or an adult who day after day thinks about the world of a novel-could be described as developing expertise in the domain of fantasy. Thus, the process of imagining the companion or the fictional world could become automatized until it is no longer consciously experienced. As the person readies him or herself for the imaginative act, the fantasy characters present themselves automatically. Their words and actions begin to be perceived, listened to, and recorded rather than consciously created. As a result, the imagined characters are experienced as speaking and acting independently. If this is an accurate account, then it should not be just the Alice Walkers and John Fowles of this world whose fictional characters are unruly. If sustained pretending automatizes the creative process, then anyone engaging in sustained pretense might experience the illusion of independent agency.

The first step in our investigation was to investigate the extent that illusion of independent agency was a common experience for writers. We wondered if writers who varied in skill and experience would report the illusion. In a pilot study 
designed as a first step in investigating this question, we analyzed information from a Webpage for writers that periodically asks questions and solicits responses from its users.

\section{PILOT INVESTIGATION}

Over a two-month period, the following question was posed to the users of www.inkspot.com, a Website for writers: How do you make your characters come to life? The responses to this question were posted on the Webpage, without any editing [24]. To determine the extent that writers discuss the illusion of independent agency spontaneously when asked about character development, we performed a content analysis of all the posted responses. Altogether 328 strategies for bringing characters to life were provided by 219 people (each respondent provided 1.5 strategies on average, with a modal response of one strategy). Two of the authors independently coded the responses and a $72.7 \%$ of the time in categorizing the strategies (disagreements were resolved by discussion). The responses categories were:

1. Listing descriptions of the character, including the character's biographical detail, physical appearance, and individuating quirks, e.g., "I sometimes keep profile cards with physical descriptions, age, etc., on them" (32.3\% of the responses);

2. Basing characters on real-life models, e.g., "I write historical romances so I read joumals and books written by people in the 19th century to get a feel for the language, customs, dress, etc." ( $24.1 \%$ of the responses);

3. Observing the characters, e.g., "I look at the character and write down what I see" and "I eavesdrop on their conversations" (18.3\% of the responses);

4. Impersonating characters by acting them out, e.g., "I role play the character to flesh them out" (11.3\% of the responses);

5. Engaging in dialogues with the characters, e.g., "My characters develop from streaks of dialogue. ... I let them ramble on, often inventing stereotypical characters for them to talk to" (7.9\% of the responses); and

6. Miscellaneous responses not fitting into the other categories $(6.1 \%$ of the responses).

Two of these response categories (observing characters and having dialogues with them) reflected elements of the illusion of independent agency. Unlike the other strategies writers reported (such as writing out character descriptions), there was an effortlessness associated with these observations. In fact, these types of responses do not actually address the posted request for strategies that help bring characters to life because these writers were describing characters that had already "come to life."

This pilot investigation provided evidence of the illusion of independent agency among this unsolicited group of people who had no way of knowing their 
responses would be coded by researchers looking for this particular phenomenon. However, performing content analysis on "data" collected for another purpose, particularly when those data are collected off a Website, allowed us very little control. We had essentially no information about the writer participants, other than the strategies they reported for character development. In fact, we had no way of verifying that they were actually writers at all and had no information about how they varied in age, experience, or any other respect. Thus, we turned next to a more controlled investigation and a more restricted sample in order to further explore the occurrence of the illusion of independent agency in fiction writers.

\section{METHOD}

\section{Participants}

We recruited writers through a newspaper, ad, flyers on campus, and word of mouth. No mention of the illusion of independent agency was made in recruitment. We asked for writers who had been writing fiction for at least five years to take part in an interview study in exchange for $\$ 10$. The 50 writers who responded ( 35 men and 15 women) ranged in age from 20 to 73 , with a mean age of 37 years. The writers varied considerably in their experience and success, ranging from an award-winning author of several published novels who supported himself entirely by writing to individuals who identified themselves as fiction writers but had not published or received payment for any of their work. The participants included two African Americans, one African, two Native Americans, and 45 Caucasian Americans. One participant was raised in Gabon and England, another in Israel, and the rest in the United States.

\section{Procedure}

Writers were first asked to complete a questionnaire that asked them about their genre of writing, whether they were published, if they earned a living either partially or completely by writing, and for demographic information. Then participants filled out two self-report individual difference measures (one male writer did not complete these measures) and were interviewed about their writing.

Davis's Interpersonal Reactivity Index (IRI) [25]

This 28-item measure of empathic tendencies includes four subscales composed of seven items each, answered on 5-point Likert scales which range from 1 ("does not describe me very well") to 5 ("describes me very well"). Items such as "I daydream and fantasize with some regularity about things that might happen to me" make up the fantasy subscale. Empathic concern for other people is tapped by items such as "I often have tender, concerned feelings for people less fortunate 
than I am." The personal distress subscale captures distress felt by the self in response to others' experiences (e.g., "I sometimes feel helpless when I am in the middle of a very emotional situation"). Finally, the perspective taking subscale assesses propensity to attempt to take other people's perspectives, with items such as "I try to look at everybody's side of a disagreement before I make a decision." Scores were computed by first reverse scoring appropriate items and then summing the responses across individual items.

\section{Bernstein and Putnam's Dissociative Experiences}

Scale (DES) [26]

This scale asks respondents to mark what percentage of the time they have the experience described in 28 items. The scale yields an overall dissociation score, as well as scores on three subscales [27]. The absorption and changeability subscale taps people's tendency to become highly engrossed in activities with items such as "Some people find that they become so involved in a fantasy or daydream that it feels as though it were really happening to them." The amnestic experiences subscale measures the degree to which dissociation causes gaps in episodic memory, with items such as "Some people have the experience of finding new things among their belongings that they do not remember buying." Finally, items such as "Some people sometimes have the experience of feeling that their body does not seem to belong to them" captures the dimension of derealization and depersonalization. An overall score and scores on the subscales were computed by averaging the responses to individual items.

\section{Writing Interview}

Next, writers were asked on a 5-point scale ( $1=$ "never"; $5=$ "always") how often they used each of the five strategies that we had identified earlier in our pilot investigation of the Webpage responses (description, real-life models, observation, impersonation, and observation). Then writers participated in a structured interview about the characters in their work. First they were asked to identify a character that stood out as particularly vivid or as their favorite. Then they were asked a series of questions about the development of that character, starting with general questions about character development (e.g., Do you feel there were different stages in the development of your character?) and leading to more explicit questions about the illusion of independent agency (e.g., Did you ever have the impression that the character was writing the story and that you were simply listening?)

The final part of the procedure was a brief questionnaire about childhood imaginary companions. Participants were asked to describe any childhood imaginary companions, and at what age the imaginary companion disappeared. 


\section{Coding}

The interviews with the writers were transcribed. Two of the authors then coded the transcripts, identifying instances in which the writer described the illusion of independent agency (IIA). Initially, we tried to distinguish between two different aspects of IIA:

- Autonomous characters reflected characters who seemed to have stepped out of the fictional frame and were acting within the writer's-not the character's - world (e.g., "I was out for a walk . . . suddenly, I felt the presence of two of the novel's more unusual characters behind me").

- Independent writing was characterized by experiencing writing as passive reporting, as opposed to active creation (not to be confused with "automatic writing," a phenomenon in which both the content and the motor behavior are sensed as being generated without will.) As an example of independent writing, one writer reported that "I see my characters like actors in a movie. I just write down what they say."

Although there were some instances that clearly represented either the autonomous characters or independent writing, the two coders only agreed $47 \%$ of the time that an instance constituted an example of autonomous characters, $67 \%$ of the time that an instance demonstrated independent writing, and $61 \%$ of the time that an instance that contained elements of both aspects of IIA. Thus, as we were unable to reliably separate the two components, IIA is treated as a unitary concept in the analyses that follow.

After individual instances of IIA were coded and counted, the coders assigned each writer's interview an overall IlA score that incorporated both the frequency of IIA instances and also the "intensity" of the experiences of IIA (e.g., reporting that a character "refused" to do what the author said was more intense than reporting that the character merely evolved on his or her own). These overall scores ranged from 0 to 3 with a score of 0 indicating that the writer did not report IIA at all, a score of 1 indicating the writer had some experience of IIA, a score of 2 indicating moderate experience involving several instances and/or moderately intense instances of IIA, and a score of 3 indicating extensive experience involving multiple instances and/or very intense instances of IIA. The correlation between the two coders for the overall scores was .89. In cases where the two coders disagreed, we used the mean of their ratings.

\section{RESULTS}

\section{Prevalence of IIA}

In the first round of coding, 187 instances of IIA were identified by at least one coder. Out of these 187,143 instances $(76 \%)$ were agreed on by both coders. Through discussion, the remaining discrepancies were resolved leaving a 


\section{2 / TAYLOR, HODGES AND KOHANYI}

total number of 169 instances. The mean number of instances was 3.38 per writer $(S D=2.08)$. The number of instances ranged from 0 to 9 . There were only four writers (out of 50) whose transcripts contained no instances of IIA. Table I provides examples of IIA from the writers' transcripts.

The mean overall IIA rating in the sample (measured on a 0 to 3 scale) was 1.64 $(S D=.87)$. Twenty-two writers were classified as having some minimal experience of IIA (a rating of 1), 19 as experiencing IIA moderately (a rating of 2), and 5 as experiencing IIA extensively (a rating of 3 ). The four writers who reported no instances of IIA received scores of 0 . The correlation between the number of instances of IIA and overall IIA scores was $.77(p<.001)$. We chose to use overall intensity as the predominant measure of IIA in the analyses that follow because it captured both frequency and intensity of IIA.

Table 1. Examples of the Illusion of Independent Agency from the Writers' Transcripts

It's like I am taking dictation. Their voices are quite alive to me; all I have to do is listen ...

I have the sensation that the character ... that the events are happening and I'm just reporting them.

I live with all of them every day. Dealing with different events during the day, different ones kind of speak. They say, " $\mathrm{Hmm}$, this is my opinion. Are you going to listen to me?"

... he was one of the few characters whom I felt lived in my house. In fact he was so present that my husband was complaining about him, saying "the one who drank all the milk is your character; he went to the refrigerator at night! "And I never had a character who would actually do that. They usually stay in my room in my computer.

One of my books has a scene that takes place in western Ireland off the Galway Bay . . . so I went there. I was standing out there in Galway Bay, in this little town, a tiny fishing village. . . . Actually seeing those places, all of a sudden I saw my guys doing this stuff, and I said, "This is where my guys are!" To be honest, I said, "Jesus, l've got to get these guys out of here! l've got to take care of these guys. This is dangerous." Waves were coming and stuff.

I was out for a walk and on my way to the grocery store. I wasn't realiy thinking all that deliberately about the novel, but suddenly, 1 felt the presence of two of the novel's more unusual characters behind me. I had the sense that if I turned around they would actually be there on the sidewalk behind me. 


\section{Individual Difference Measures and IIA}

The results for the Davis Interpersonal Reactivity index are reported in Table 2, as a function of gender. In this sample, females scoted higher than males, which replicates past research with this measure [28]. However, the more interesting finding was that both men and women in the sample of writers scored significantly above general population male and female norms on all four subscales of Davis's IRI [28].

The writers also scored higher than general population norms on the Dissociative Experiences Scale. The mean score across all 28 items on the DES in our sample of writers was $18.52(S D=16.07)$, ranging from a minimum of 1.43 to a maximum of 42.14 . This mean is significantly higher from the average DES score of 7.8 found in a general population sample of $415[27], t(48)=8.05, p<.001$.

Table 2. Writer's Scores on the Subscales of Davis's IRI, Compared to Normal Values

\begin{tabular}{lcccc}
\hline & $\begin{array}{c}\text { Writer's } \\
\text { Mean }(S D)\end{array}$ & $\begin{array}{c}\text { Norm (from } \\
\text { Davis, 1979) }\end{array}$ & t Value & p Value \\
\hline $\begin{array}{l}\text { Males }(N=34)^{a} \\
\text { Fantasy }\end{array}$ & $27.32(5.01)$ & $15.73(5.60)$ & 13.48 & $<.001$ \\
$\begin{array}{l}\text { Perspective } \\
\text { taking }\end{array}$ & $26.03(4.63)$ & $16.78(4.72)$ & 11.64 & $<.001$ \\
$\begin{array}{l}\text { Empathic } \\
\text { concern }\end{array}$ & $27.94(4.90)$ & $19.04(4.21)$ & 10.58 & $<.001$ \\
$\begin{array}{l}\text { Personal } \\
\text { distress }\end{array}$ & $15.76(5.63)$ & $9.46(4.55)$ & 8.22 & $<.001$ \\
$\begin{array}{l}\text { Females }(N=15) \\
\text { Fantasy }\end{array}$ & $30.13(3.85)$ & $18.75(5.17)$ & 11.44 & $<.001$ \\
$\begin{array}{l}\text { Perspective } \\
\text { taking }\end{array}$ & $27.87(3.46)$ & $17.96(4.85)$ & 11.08 & $<.001$ \\
$\begin{array}{l}\text { Empathic } \\
\text { concern }\end{array}$ & $28.67(4.67)$ & $21.67(3.83)$ & 5.80 & $<.001$ \\
$\begin{array}{l}\text { Personal } \\
\text { distress }\end{array}$ & $16.33(4.47)$ & $12.28(5.01)$ & 2.79 & .014 \\
\hline
\end{tabular}

${ }^{a}$ One male subject did not complete the IRI. 
In fact, the writers' scores are closer to the average DES score for a sample of 61 schizophrenics (schizophrenic $M=17.7$ ) [27]. Seven of the writers scored at or above 30, a commonly used cutoff for "normal scores" [29]. There was no difference between men's and women's overall DES scores in our sample, a finding consistent with results found in other studies of normal populations [26].

With these comparisons, our goal is to highlight the unusually high scores for our writers, not to suggest that they were psychologically unhealthy. Although scores of 30 or above are more common among people with dissociative disorders (such as Dissociative Identity Disorder), scoring in this range does not guarantee that the person has a dissociative disorder, nor does it constitute a diagnosis of a dissociative disorder [27, 29]. Looking at the different subscales of the DES, it is clear that our writers deviated from the norm mainly on items related to the absorption and changeability factor of the DES. Average scores on this subscale $(M=26.22, S D=14.45)$ were significantly different from scores on the two subscales that are particularly diagnostic for dissociative disorders: derealization and depersonalization subscale $(M=7.84, S D=7.39)$ and the amnestic experiences subscale $(M=6.80, S D=8.30), F(1,48)=112.49, p<.001$. These latter two subscales did not differ from each other, $F(1,48)=.656, p=.42$. Seventeen writers scored above 30 on the absorption and changeability scale, whereas only one writer scored above 30 on the derealization and depersonalization scale and only one writer (a different participant) scored above 30 on the amnestic experiences scale.

A regression analysis using the IRI subscales (fantasy, empathic concern, perspective taking, and personal distress) and the DES subscales (absorption and changeability, amnestic experiences, and derealization and depersonalization) to predict overall IIA was run. The overall model was not significant $r^{2}=.22$, $F(7,41)=1.63, p=.15$. However, writers who had higher IIA scores scored higher on the fantasy subscale of IRI, $b=.333, t(48)=2.04, p<.05$ and marginally lower on the empathic concem subscale, $b=-.351, t(48)=-1.82, p<.10$ (all betas are standardized). Because not all of the items on the DES are included in one of the three subscales, we also ran a regression model predicting overall IIA from the mean score across DES items. Neither the $r^{2}$ nor the standardized beta for total DES scores was significant in this analysis.

\section{Imaginary Companions and IIA}

Twenty-one of our writers reported that they had imaginary companions as children; 29 reported that they did not. Five of the writers reported that they still had their imaginary companions from childhood. Overall IlA scores did not differ significantly between writers who reported having ICs $(M=1.55, S D=.89)$ and those who did not $(M=1.71, S D=.86), t(48)=.636, p=.53$. In a pattem resembling our results on the other individual difference measures, having an imaginary companion did not predict IIA, but our writers as a whole looked 
different from the general population. Forty-two percent of our writers recalled having an imaginary companion; whereas Schaefer found that only $18 \%$ of a sample of high school students reported having had an imaginary companion in childhood [30]. Qualitatively, the descriptions of the imaginary companions of the writers in our sample were noteworthy for detail and uniqueness. Table 3 provides examples of the ICs described by the writers in this sample. The description of Eyabra, Akoum, and Duke in Table 3 is particularly interesting because they were created when the writer was growing up in nural Gabon. There is very little cross-cultural research on imaginary companions, but this description suggests that imaginary companions are not unique to Western cultures.

\section{IIA and Success as a Writer}

Seventeen of the writers in our sample were published; 33 were not. Writers who were published had marginally higher IIA scores $(M=1.80, S D=.81)$ than

Table 3. Examples of the Writers' Descriptions of Imaginary Companions

Pepper, Crayon, and Golliwod: Three invisible "sheas," a type of invisible flea. Pepper was pink with pink hair, Crayon was plaid, and Golliwod was black with black hair. The child carried them around and protected them from the evil planet aliens who were looking for them.

Pucka: Pucka was an invisible guardian angel who talked to the child and listened to her. "It was warm and accepting. I used to have a strong sense of Pucka when I fell asleep at night and a couple of times I caught a glimpse. He glowed and was more animalistic than human."

Eyabra, Akoum, and Duke: Three invisible imaginary companions who worked together as a team. Eyabra was a mask with three faces (one large and two small ones), Akoum was a magic green staff, and Duke was a huge shield made of a turtle's case shell. "Depending on the time of day, a face from the mask would tell me stories while I sat on the shell and the staff kept watch."

Johann: "It was a couch-caster-a little hemisphere of metal that went on the bottom of a couch-leg to keep the carpet from tearing or something. I wore it on my thumb and my thumb and the caster-cap became Johann. I was three when it first appeared. The dentist told my parents that I had to quit sucking my thumb because it was affecting my bite, so I thought of the idea of Johann to keep myself from sucking my thumb. It was male and human, even though its outward visible form was a caster, I still thought of it as human. I would talk to it when alone, and telepathically to it in the company of others. It didn't speak to me as much as it spoke to other people. I felt secure when thinking about or actually in the company of Johann. Everyone knew about Johann. There were even several kidnapping attempts made on Johann." 
those who were not published $(M=1.32, S D=.92), t(48)=1.90, p=.06$. We found the same pattern of results (although also not significant), when we divided the writers into those who earned no income from writing $(N=27)$ and those who supported themselves either partially or completely from writing $(N=23)$. The latter group received higher IIA scores $(M=1.80, S D=.84)$ than the former $(M=1.50, S D=.89)$.

\section{IIA and Sex of Writer}

The female writers in our sample received marginally higher overall IIA scores $(M=2.00, S D=.89)$ than the men $(M=1.49, S D=.83), t(48)=1.97, p=.05$. In order to explore this difference further, we looked for sex differences in the degree to which male and female writers reported using the various character development techniques identified in the pilot study. Women reported "observing" their characters (one of the strategies that we earlier had identified as reflecting IIA) more often than men did, $t(48)=2.29, p<.05$; the means were $4.60(S D=.74)$ and $3.94(S D=1.00)$, respectively. Interestingly, not only was this strategy the only one for which frequency of use differed between the sexes, it was also the only strategy for which frequency of use correlated significantly with overall IIA ratings, $r=.46, p=.001$.

\section{DISCUSSION}

Our exploration of the relationship between adult fiction writers and their characters suggests that the experience of imaginary others as having minds of their own is common. Almost everyone ( $92 \%$ ) in our sample reported at least some experience of the illusion of independent agency. All the participants seemed to understand what we were asking about, and none of them looked at the interviewer in confusion when they were asked questions about whether they interacted with and heard the voices of people who were not real. Furthermore, the writers provided vivid examples of their characters who not only had taken over the job of composing their own life stories, but who also sometimes actively resisted the writer's attempts to control the story. Furthermore, some of the fictional characters were experienced as sometimes leaving the pages of the writers' stories to inhabit the writers' everyday worlds (e.g., wandering around in the house).

The downside of this nearly universal experience of ILA in our writers was that the minimal variance made it more difficult to investigate the extent to which experiencing the illusion was related to other characteristics of the writers within our sample. We had hoped initially to identify markers that differentiated writers who experienced IIA from those who did not. Given that nearly all the writers experienced IIA, we instead attempted to look for ways to predict who experienced it the most.

We found some evidence that more frequent and intense experiences of IIA might facilitate writing. In our sample, there was a trend for published writers 
to demonstrate greater overall levels of the illusion of independent agency than unpublished writers. Future research might tap additional measures of writer "success," for example examining whether works containing characters perceived by authors to be autonomous are more popular among readers. Perhaps a certain amount of autonomy in characters makes them more compelling. As André Gide puts it: "the poor novelist constructs his characters, he controls them and makes them speak. The true novelist listens to them and watches them function; he eavesdrops on them even before he knows them. It is only according to what he hears them say that he begins to understand who they are" [31, p. 38].

Neither scores on the IRI, a measure of empathic tendencies, nor the DES, a measure of dissociative tendency, predicted IIA. The most striking result here was that the writers seemed to differ from the rest of the population. The writers as a whole scored higher than average on all four subscales of the IRI, and were particularly off the charts for the fantasy and perspective-taking subscales. These two subscales tap the components of empathy that seem most conceptually related to IIA and might be seen as "grown-up" versions of variables associated with children who have imaginary companions (pretend play and theory of mind skills).

Similarly, the writers scored higher than average on the DES, although, as a group, they did not appear to have unhealthy levels of dissociation. In particular, the writers differed most from general population norms on the absorption and changeability subscale of the DES, which measures the component of dissociation considered least likely to be related to pathological experiences [32]. The profile of our writers that emerges from these two individual difference measures is that of a group of people who readily adopt other people's perspectives and who revel in the imaginative worlds of fictional characters, fantasy, and daydreams.

Finally, having an imaginary companion as a child did not predict greater levels of IIA, but once again, our sample looked different from the general population in their retrospective reports of imaginary companions. The percentage of writers reporting that they had imaginary companions as children was more than twice that found in a study of normal high school students [30]. Given that the mean age in our sample of writers was 37 (well beyond high school), it is all the more impressive that this percentage remembered having imaginary companions.

The higher than average percentage of imaginary companions reported by our writers could reflect a higher base rate of imaginary companions in childhood than is found among non-writers. Alternatively (or additionally), it is possible that writers have more memorable childhood imaginary companions. Writers may have had companions who were more highly elaborated or vivid, who attracted the attention of adult caregivers such as parents (who may later remind and tell their children about their imaginary companions), or who actually never completely disappeared as the future writers grew up (as was the case for the five writers in our sample who reported still having their imaginary companions from childhood). In addition to their frequency, the imaginary companions described by the writers were noteworthy for both detail and uniqueness. 
Thus, on a variety of dimensions related to imagination and pretense, our writers may very well be outliers-after all, they were eligible for our study because of their dedication to the fantasy-oriented activity of fiction writing. However, it is possible that our fiction writers differ from other adults more in the time devoted to inventing imaginary others than in a general disposition to enjoy fantasy. Fiction writers have a job (or at least a serious hobby) that has them spending a great deal of time thinking about their characters. Similarly imaginative individuals who put their talents to work in some other profession, such as teaching kindergartners, designing software, or running a recycling center, might not experience the illusion of independent agency because their imaginative activities do not involve precisely the act of inventing other people. On the other hand, we wonder if there is a similar or analogous type of illusion to IIA that is associated with careers involving the prediction of behavior in other people, as is the case in trial law, marketing, and politics. Like the fiction writers who start with a description of their fictional character, people whose jobs lead them to think about the opinions and activities of others may find that perspective taking becomes automatized.

Fiction writers are particularly interesting because they are fantasy-oriented to begin with and they develop additional imaginative skills on the job. The intersection of these two factors produces the fascinating illusion of independent agency that was so prevalent in the fiction writers we interviewed. But just as the activities of our fiction writers might represent an extreme form of imaginative behavior, it must be noted that imaginative experiences, including interactions with imaginary companions, also span a diverse range in children. Some children have highly vivid imaginary companions who are reported to engage in autonomous behavior, other children merely have a doll or stuffed animal who serves as a companion, and yet others tend to interact with a host of different imaginary characters, none of whom has a sustained existence or is developed in any depth [7]. The question of how different forms of pretend play in childhood can predict adult imaginative behavior is an intriguing one $[5,6,33]$.

We are not the first to see a connection between children pretending and adults writing fiction. In 1908, Freud wrote, "Might we not say that every child at play behaves like a creative writer, in that he creates a world of his own ..." $[34$, p. 143]. Freud hoped to develop an account of the creative process by identifying an activity that was related to creative writing, but more easily examined. For this purpose, he suggested that pretend play in children might be the key to understanding the process of adult fiction writing. He paralleled the two by noting that both children and writers create an imaginary world, enliven it with real life material, and take it seriously to heart, while still keeping it separate from reality. But just as childhood pretense might provide clues about the creative process in adults, the study of adult fantasy could lead to a better understanding of what is going on when children pretend. In any case, the similarities we found between children's imaginary companions and the characters of fiction writers 
support the emerging view that there may be considerable continuity in the imaginative lives and experiences of children and adults.

\section{REFERENCES}

1. G. G. Fein, Pretend Play: An Integrative Review, Child Development, 52, pp. 1095$1118,1981$.

2. I. Bretherton, Pretense: The Form and Function of Make-Believe Play, Developmental Review, 9, pp. 383-401, 1989.

3. M. Taylor and S. M. Carlson, Imaginary Companions and Elaborate Fantasy in Childhood: Discontinuity with Nonhuman Animals, in Pretense in Animals and Humans, R. W. Mitchell (ed.), Cambridge University Press, Cambridge, pp. 167-182, 2002.

4. J. Piaget, Play, Dream, and Imitation in Childhood, Norton, New York, 1962.

5. D. G. Singer and 3. L. Singer, The House of Make-Believe: Children's Play and the Developing Imagination, Harvard University Press, Cambridge, Massachusetts, 1990.

6. J. D. Woolley, Thinking about Fantasy: Are Children Fundamentally Different Thinkers and Believers from Adults? Child Development, 68:6, pp. 991-1011, 1997.

7. M. Taylor, Imaginary Companions and the Children Who Create Them, Oxford University Press, New York, 1999.

8. F. Kahlo, The Diary of Frida Kahlo: An Intimate Self-Portrait (Introduction by Carlos Fuentes, essay by Sarah M. Lowe), Harry N. Abrams, Inc., New York, 1995.

9. N. Bloomfield (Director), Kurt and Courtney, Fox Lorber Distributors, Los Angeles, 1998.

10. M. Watkins, The Development of Imaginal Dialogues: Invisible Guests, Sigo Press, Boston, 1990.

11. A. Walker, In Search of Our Mother's Garden, Harcourt-Brace Jovanovich, New York, 1983.

12. J. K. Rowling, Radio Interview on The Diane Rehm Show, NPR, October, 1999.

13. P. Pullman, unpublished interview with $\mathrm{M}$. Taylor, 2002.

14. J. Cary, Art and Reality, Cambridge University Press, Cambridge, United Kingdom, 1958.

15. J. Fowles, The French Lieutenant's Woman, Little, Brown \& Company, Boston, 1969.

16. E. M. Forster, Aspects of the Novel, Harcourt Brace, New York, 1927/1985.

17. B. Stoney, Enid Blyton: A Biography, Hodder, London, 1974.

18. M. E. Ansfield and D. M. Wegner, The Feeling of Doing, in The Psychology of Action, P. M. Gollwitzer and J. A. Bargh (eds.), Guilford Press, New York, pp. 482-506, 1996.

19. D. M. Wegner and T. Wheatley, Apparent Mental Causation: Sources of the Experience of Will, American Psychologist, 54:7, pp. 480-492, 1999.

20. M. K. Johnson, Discriminating the Origin of Information, in Delusional Beliefs, T. F. Oltmanns and B. A. Maher (eds.), John Wiley, New York, pp. 34-65, 1988.

21. M. Csikszentmihalyi, Flow: The Psychology of Optimal Experience, Harper \& Row, New York, 1990.

22. S. K. Perry, Writing in Flow: Keys to Enhanced Creativity, Writer's Digest, Cincinnati, Ohio, 1999.

23. H. L. Dreyfus and S. E. Dreyfus, Mind Over Machine, The Free Press, New York, 1986.

24. D. Ridpath Ohi, personal communication, 1997. 
25. M. H. Davis, Measuring Individual Differences in Empathy: Evidence for' a' Multidimensional Approach, Journal of Personality and Social Psychology, 44:1, pp. 113-126, 1983.

26. E. M. Bernstein and F. W. Putnam, Development, Reliability, and Validity of a Dissociation Scale, The Journal of Nervous and Mental Disease, 174:12, pp. 727-735, 1986.

27. E. B. Carlson and F. W. Putnam, Manual for the Dissociative Experiences Scale, Beloit College, Beloit, Wisconsin, 1992.

28. M. H. Davis, A Multidimensional Approach to Individual Differences in Empathy, Catalog of Selected Documents in Psychology, 10, p. 85, 1985.

29. N. G. Waller, F. W. Putnam, and E. B. Carlson, Types of Dissociation and Dissociative Types: A Taxometric Analysis of Dissociative Experiences, Psychological Methods. l:3, pp. 300-321, 1996.

30. C. Schaefer, Imaginary Companions and Creative Adolescents, Developmental Psychology, I, pp. 747-749, 1969.

31. S. B. Chatman, Story and Discourse, Cornell University Press, Ithaca, New York, 1978.

32. C. A. Ross, S. Joshi, and R. Currie, Dissociative Experiences in the General Population, Hospital and Community Psychiatry, 42:3, pp. 297-301, 1991.

33. K. L. Walton, Mimesis as Make-Believe: On the Foundations of the Representational Arts, Harvard University Press, Cambridge, Massachusetts, 1990.

34. S. Freud, Creative Writers and Day-Dreaming, S.E., 9, 1908.

Direct reprint requests to:

Marjorie Taylor

Department of Psychology

1227 University of Oregon

Eugene, OR 97403-1227

e-mail: mtaylor@uoregon.edu 